\title{
Validating a Lower Urine Output Criteria in Predicting Death in Critically III Patients
}

\author{
Azrina Md Ralib, Mohd Basri Mat Nor \\ Department of Anaesthesiology and Intensive Care, Kulliyyah (Faculty) of Medicine, International Islamic \\ University Malaysia, International Islamic University Malaysia, Jalan Hospital Campus, 25000 Kuantan, \\ Pahang, Malaysia
}

\section{ABSTRACT}

Introduction: Urine output provides a rapid estimate for kidney function, and its use has been incorporated in the diagnosis of acute kidney injury. However, not many studies had validated its use compared to the plasma creatinine. It has been showed that the ideal urine output threshold for prediction of death or the need for dialysis was $0.3 \mathrm{ml} / \mathrm{kg} / \mathrm{h}$. We aim to assess this threshold in our local ICU population. Methods: This was a secondary analysis of an observational study done in critically ill patients. Hourly urine output data was collected, and a moving average of 6-hourly urine output was calculated over the first 48 hours of ICU admission. $\mathrm{AKI}_{\mathrm{uo}}$ was defined if urine output $\leq 0.5 \mathrm{ml} / \mathrm{kg} / \mathrm{h}$, and $\mathrm{UO}_{0.3}$ was defined as urine output $\leq 0.3$ $\mathrm{ml} / \mathrm{kg} / \mathrm{h}$. Results: 143 patients were recruited into the study, of these, $87(61 \%)$ had $\mathrm{AKI}_{\text {uo }}$, and $52(36 \%)$ had $\mathrm{UO}_{0.3}$. The AUC of $\mathrm{AKI}_{\mathrm{uo}}$ in predicting death was 0.62 (0.51 to 0.72$)$, and $\mathrm{UO}_{0.3}$ was 0.66 (0.55 to 0.77 ). There was lower survival in patients with $\mathrm{AKI}_{\mathrm{uo}}$ and $\mathrm{UO}_{0.3}$ compared to those without $(\mathrm{p}=0.01$, and 0.001 , respectively). However, only $\mathrm{UO}_{0.3}$ but not $\mathrm{AKI}_{\mathrm{uo}}$ independently predicted death (HR 2.44 (1.15 to 5.18). Conclusions: A threshold of 6 hourly urine output of $0.3 \mathrm{ml} / \mathrm{kg} / \mathrm{h}$ but not $0.5 \mathrm{ml} / \mathrm{kg} / \mathrm{h}$ independently predictive of death. This support previous finding of a lower threshold of urine output criteria for optimal prediction.

KEYWORDS: Urine Output, Intensive Care Unit, Acute Kidney Injury, Death, Dialysis

\section{INTRODUCTION}

Urine output is one of the first biomarker for acute kidney injury (AKI). ${ }^{1}$ Clinically, it provides the earliest indication of kidney dysfunction in the critical care settings where they are routinely measured. Its use in the diagnosis and classification of AKI was first included in the Risk Injury Failure Loss and End Stage Renal Failure (RIFLE), and later incorporated in the Acute Kidney Injury Network

Corresponding author:

Dr Azrina Md Ralib

Department of Anaesthesiology and Intensive Care, Kulliyyah (Faculty) of Medicine, International Islamic University Malaysia, Jalan Hospital Campus, 25000 Kuantan, Pahang, Malaysia

Email: drazrina@gmail.com

Phone: (+6) 016-9223406

Fax: (+6) 09-5143402
(AKIN), and the recent Kidney Diseases: Improving Global Outcome (KDIGO) classifications. ${ }^{2-4}$ In these guidelines, urine output of $\leq 0.5 \mathrm{ml} / \mathrm{kg} / \mathrm{h}$ was defined as AKI, and this was mainly based on consensus opinion amongst experts. ${ }^{5}$ Using this definition, the incidence of AKI reported was higher compared to AKI defined by creatinine criteria. ${ }^{6-10}$ Higher death was reported in patients with AKI by urine output compared to those without AKI, , 11 however, the death was lower when compared to those with AKI by plasma creatinine. ${ }^{9,12}$

Recently, in a study of 725 ICU admissions, Ralib et al. ${ }^{6}$ showed that the ideal urine output threshold for prediction of hard outcome, death or the need for dialysis was $0.3 \mathrm{ml} / \mathrm{kg} / \mathrm{h}$ for moving block of 6 hours urine output. The ideal threshold depends on duration of urine output assessment, as defined in the threshold line $[(0.03 \times$ duration of assessment $)+$ $0.11 \mathrm{ml} / \mathrm{kg} / \mathrm{h}$ for duration between 3 and 9 hours. We aimed to compare this urine output threshold to the current threshold in AKI definition in diagnosing 
AKI by creatinine criteria and predicting death or the need for dialysis. In addition, we assessed different duration of assessment from 1 to 12 hours over the first 48 hours of ICU admission.

\section{MATERIAL AND METHODS}

This was a secondary analysis of a single centre, prospective observational study of Hospital Tengku Ampuan Afzan, Kuantan. ${ }^{13}$ The study was registered under the National Medical Research Register (NMRR-13-1631-18970). Ethical approval was obtained from the Malaysian Medical Ethics and Research Committee (MREC Number P14-663), and the International Islamic University Ethics Committee (IREC Number 266). All patients more than 18 years being admitted to ICU were reviewed. As only routinely available clinical information is collected, the need for informed consent is waived. Patients' clinical records and ICU charts were reviewed.

Inclusion criteria includes age more than 18 years old who stayed in the ICU longer than 48 hours, and exclusion criteria includes ICU admission of less than 48 hours, post elective surgery, and ICU readmission. Hourly urine output and fluid input data for the first 48 hours of admission were collected. A moving average urine output over 6 hours over body weight was calculated for the first $48^{\text {th }}$ hour post ICU admission (Figure 1).

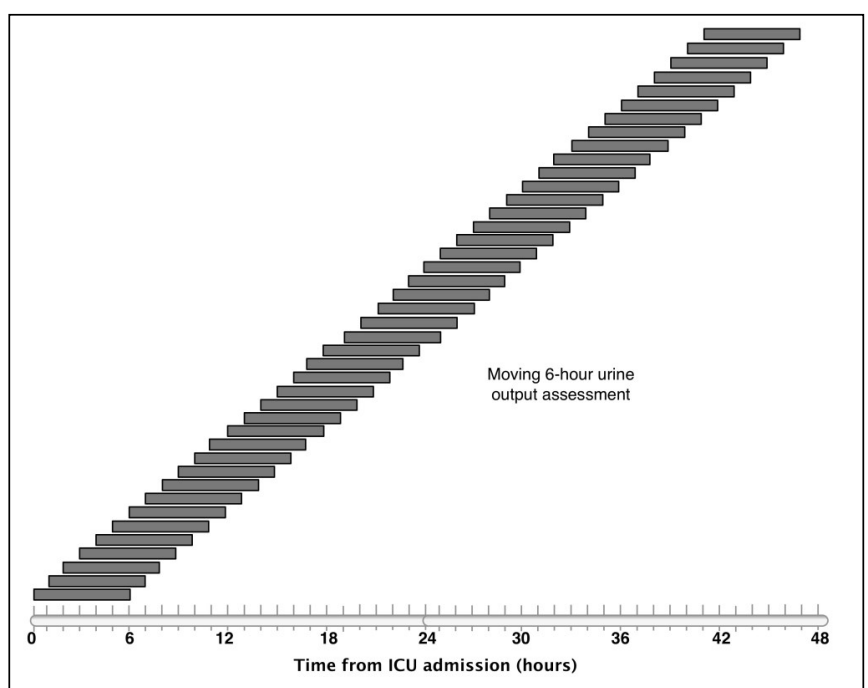

Figure 1: Urine output assessed over a moving block of 6 hours duration. These were calculated for the first 48 hours of ICU admission.

The minimum urine output volume calculated was divided by the body weight. $\mathrm{AKI}_{\mathrm{uo}}$ was defined if urine output $\leq 0.5 \mathrm{ml} / \mathrm{kg} / \mathrm{h}$, and $\mathrm{UO}_{0.3} \leq 0.3 \mathrm{ml} / \mathrm{kg} /$ h. In addition, urine output over a moving block from 1 to 12 hour was determined.

Daily plasma creatinine concentrations measured in the ICU were collected from the patients' clinical records. $\mathrm{AKI}_{\mathrm{Cr}}$ was defined as creatinine increase of

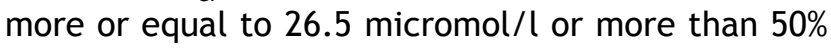
increase from first creatinine on ICU admission.
Plasma creatinine was analysed using the Olympus $\mathrm{AU}_{2700}{ }^{\mathrm{TM}}$ chemistry-immunoanalyser (Olympus, Philadelphia, USA). Other data that were collected includes age, sex, height, weight, ethnicity, clinical or surgical admission, primary admission diagnosis, co-morbid diseases, length of ICU and hospital stay, duration of mechanical ventilation, death, and the need for dialysis. The baseline Sequential Organ Failure Assessment (SOFA) and Acute Physiological and Chronic Health Evaluation II (APACHE II) scores were used to assess severity of illness in each patient.

\section{Statistical Analysis}

Statistical analysis was performed using PASW ${ }^{\circledR}$ version 18.0 (IBM, Somers, New York, USA), PRISM 5.0 ${ }^{\circledR}$ (Graph Pad, La Jolla, California, USA), and MatLab 2011b (MathWorks, Natick, MA, USA). Results are presented as mean \pm SD or median (inter-quartile range), and comparison of variables between the two groups was analyzed using the independent t-test or the Mann-Whitney. Categorical variables were compared with Chi-Square test for independent variables. The diagnostic, predictive or prognostic performance of biomarkers were assessed by the area under curve (AUC) of receiver operating characteristic (ROC) curve of the sensitivity (true positive rate) against 1 -specificity (false positive rate) across a series of cut-off points (e.g. biomarkers concentration). (14) The AUC ranges from 0.5 (no discrimination) to 1 (perfect discrimination). ${ }^{(15,16)}$ Clinical validity is assumed at an AUC of more than 0.70 . The analyses were calculated for the outcome variables of $\mathrm{AKI}_{\mathrm{Cr}}$, death and the need for dialysis. The variables investigated against these outcomes include urine output data (numerical variable), $\mathrm{AKI}_{\mathrm{uo}}$ and $\mathrm{UO}_{0.3}$ (categorical variable). The optimal cut-off point was defined as the measured quantity, which maximised sensitivity and specificity. ${ }^{17}$ Sensitivity (true positive) and specificity (false positive) of the urine output criterion for prediction of death were calculated for each cut-off point. Logistic regression analysis was used to calculate the odds ratios after adjusting for covariates. Backward stepwise logistic regression automatic variable selection procedure was used. Odds ratio (OR) from the logistic regression described the strength of association of each variable with outcomes which includes $\mathrm{AKI}_{\mathrm{Cr}}$, mortality and death. Analysis of survival was performed using Kaplan Meier and Cox-regression analyses.

\section{RESULTS}

Three hundred and ten patients were screened between $21^{\text {st }}$ February 2014 to $3^{\text {rd }}$ May 2014. Patients less than 18 years $(n=20)$, with ICU admission of less than 48 hours $(n=112)$, post elective surgery $(n=27)$, and ICU readmission $(n=8)$ were excluded. A total of 143 patients were recruited, of these $87(61 \%)$ had $\mathrm{AKI}_{\mathrm{uo}}$, and 52 (36\%) had $\mathrm{UO}_{0.3}$. 
Demographic, clinical characteristics and outcomes

Table 1 showed the demographic profiles and outcomes between those with and without $\mathrm{AKI}_{\text {uo }}$. Patients with $\mathrm{AKI}_{\text {uo }}$ were older and had higher severity of illness than those without $\mathrm{AKI}_{\text {uo }}$ More patients with $\mathrm{AKI}_{\mathrm{uo}}$ had sepsis and septic shock compared to those without $\mathrm{AKI}_{\mathrm{uo}}$. Eighty-four patients $(59 \%)$ had persistent hypotension needing support of inotropic and vasoconstrictor agent. Of these, $62(74 \%)$ had AKI, compared to only $42 \%$ of those without hypotension $(p<0.0001)$. Thirty-six patients $(25 \%)$ were from surgical based, of which 30 undergoing emergency surgery. More patients from the medical category had $\mathrm{AKI}_{\mathrm{uo}}$ compared to those from surgical category $(p=0.006)$.

Table 1: Demographic and clinical characteristics

\begin{tabular}{|c|c|c|c|c|}
\hline Variables & All patients $(n=143)$ & $\mathrm{AKI}_{\text {uo }}(\mathrm{n}=87)$ & No $A_{K I_{\text {uo }}(n=56)}$ & $p$-value \\
\hline \multicolumn{5}{|l|}{ Numerical variables } \\
\hline Age (years) & $50(16)$ & $53(16)$ & $47(17)$ & 0.029 \\
\hline Weight (kg) & $67(15)$ & $68(17)$ & $66(12)$ & 0.336 \\
\hline Height $(\mathrm{cm})$ & $159(17)$ & $161(8)$ & $162(9)$ & 0.115 \\
\hline SOFA score & $7.7(3.7)$ & $8.7(3.7)$ & $6.2(3.2)$ & $<0.0001$ \\
\hline APACHE I| score & $17.1(6.7)$ & $19.5(6.3)$ & $13.5(5.8)$ & $<0.0001$ \\
\hline $\begin{array}{l}\text { Duration of mechanical ventilation } \\
\text { (days) }\end{array}$ & $4.41(6.69)$ & $5.04(6.82)$ & $3.76(6.23)$ & 0.176 \\
\hline Length of stay ICU (days) & $5.67(7.28)$ & $6.39(7.74)$ & $5.39(7.08)$ & 0.563 \\
\hline Length of stay hospital (days) & $13.8(14.7)$ & $14.0(14.9)$ & $13.4(14.4)$ & 0.980 \\
\hline \multicolumn{5}{|l|}{ Categorical variables } \\
\hline Ethnicity & & & & 0.319 \\
\hline Malay & $110(76.9)$ & $67(77.0)$ & $43(76.8)$ & \\
\hline Chinese & $17(11.9)$ & $12(13.8)$ & $5(8.9)$ & \\
\hline Indian & $4(2.8)$ & $2(2.3)$ & $2(3.6)$ & \\
\hline Orang Asli & $7(4.9)$ & $5(5.7)$ & $2(3.6)$ & \\
\hline Others & $5(3.5)$ & $1(1.1)$ & $4(7.1)$ & \\
\hline Gender (Male) & $92(64.3)$ & $57(65.5)$ & $35(62.5)$ & 0.713 \\
\hline Admission Category & & & & 0.0006 \\
\hline Medical & $107(74.8)$ & $72(82.8)$ & $35(62.5)$ & \\
\hline Surgical & $36(25.2)$ & $15(17.2)$ & $21(37.5)$ & \\
\hline Hypotension needing support & $84(58.7)$ & $62(73.8)$ & $25(42.4)$ & $<0.0001$ \\
\hline Frusemide & $34(23.8)$ & $26(29.9)$ & $8(14.3)$ & 0.079 \\
\hline Nephrotoxic drugs & $12(8.4)$ & $7(8.0)$ & $5(8.9)$ & 0.853 \\
\hline Sepsis & $79(55.2)$ & $55(63.2)$ & $24(42.9)$ & 0.017 \\
\hline Septic Shock & $51(35.7)$ & $42(48.3)$ & $9(16.1)$ & $<0.0001$ \\
\hline Primary Admission Category & & & & 0.005 \\
\hline Neurological & $16(11.2)$ & $10(17.9)$ & $6(6.9)$ & \\
\hline Respiratory & $53(37.1)$ & $38(43.7)$ & $15(26.8)$ & \\
\hline Infection & $19(13.3)$ & $13(14.9)$ & $6(10.7)$ & \\
\hline Connective Tissue & $4(2.8)$ & $2(2.3)$ & $2(3.6)$ & \\
\hline \multicolumn{5}{|l|}{ Disase/Autoimmune } \\
\hline Renal & $4(2.8)$ & $4(4.6)$ & $0(0)$ & \\
\hline Cardiovascular & $12(8.4)$ & $5(5.7)$ & 7 (12.5) & \\
\hline $\begin{array}{l}\text { Gastrointestinal/ Hepatobiliary/ } \\
\text { Pancreas }\end{array}$ & $13(9.1)$ & $11(12.6)$ & $2(3.6)$ & \\
\hline Trauma & $20(14.0)$ & $6(6.9)$ & $14(25.0)$ & \\
\hline Endocrine/Metabolic & $1(0.7)$ & $1(1.1)$ & $0(0)$ & \\
\hline Others & $1(0.7)$ & $1(1.1)$ & $0(0)$ & \\
\hline \multicolumn{5}{|l|}{ Comorbid Diseases } \\
\hline Hypertension & $52(36.4)$ & $36(41.4)$ & $16(28.6)$ & 0.120 \\
\hline Diabetes mellitus & $41(28.7)$ & $33(37.9)$ & $8(14.3)$ & 0.002 \\
\hline Chronic cardiovascular disease & $13(9.1)$ & $7(8.0)$ & $6(10.7)$ & 0.588 \\
\hline Chronic renal failure & $14(9.8)$ & $13(14.9)$ & $1(1.8)$ & 0.022 \\
\hline Chronic lung disease & $16(11.3)$ & $11(12.6)$ & $5(8.9)$ & 0.492 \\
\hline Chronic liver disease & $1(0.7)$ & $1(1.1)$ & 0 & 0.421 \\
\hline Immunosuppression/HIV & $3(2.1)$ & $0(0)$ & $3(5.4)$ & 0.029 \\
\hline Cancer & 7 (4.9) & $4(4.6)$ & $3(5.4)$ & 0.837 \\
\hline Others & $11(7.7)$ & $8(9.2)$ & $3(5.4)$ & 0.400 \\
\hline Vasopressor therapy & $87(60.8)$ & $63(72.4)$ & $24(42.9)$ & 0.001 \\
\hline Dialysis & $37(25.9)$ & $33(37.9)$ & $4(7.1)$ & $<0.0001$ \\
\hline CRRT & $13(9.1)$ & $14(16.1)$ & $0(0)$ & 0.002 \\
\hline Intermittent Haemodialysis & $21(14.7)$ & $17(19.5)$ & $4(7.1)$ & \\
\hline Peritoneal Dialysis & $1(0.7)$ & $1(1.1)$ & $0(0)$ & \\
\hline SLED & $1(0.7)$ & $1(1.1)$ & $0(0)$ & \\
\hline Mortality & $33(23.1)$ & $26(29.9)$ & $7(12.5)$ & 0.016 \\
\hline Mechanical ventilation & $138(96.5)$ & $85(97.7)$ & $53(94.6)$ & 0.331 \\
\hline
\end{tabular}

Data expressed as mean (SD), or median (interquartile range) for numerical variables, and $n$ (\%) for categorical variables. Comparisons for numerical variables were performed using independent t-test for parametric data, and Man Whitney test for non-parametric data. Comparisons for categorical variables were performed using Chi-Square test. APACHE II Score: Acute Physiological and Chronic Health Evaluation II Score. SOFA Score: Sequential Organ Failure Assessment. CRRT: Continuous renal replacement therapy. SLED: Sustained Low Efficiency Dialysis. 
Twelve patients $(8.4 \%)$ had severe traumatic brain injury (TBI), and 8 (5.6\%) were post trauma with other injuries i.e. fracture mandible, polytrauma, intraabdominal and long bone injuries. Two patients had rhabdomyolysis. One patient had motor vehicle accident with spleen laceration and left femur degloving injury had rhabdomyolysis with creatinine kinase (CK) of up to $47,000 \mathrm{U} / \mathrm{L}$. The patient had AKI stage 3 based on creatinine, and was dialysed. The average hourly urine output for this patient ranges from 0.36 to $0.45 \mathrm{ml} / \mathrm{kg} /$ hour. Another one was with status epilepticus with CK of up to 53,000 U/L. The patient had AKI stage 3 based on creatinine and was dialysed. The average hourly urine output for this patient ranges from 0.43 to $0.60 \mathrm{ml} / \mathrm{kg} / \mathrm{hour}$.

Fourteen patients had pre-existing CKD. Of these, 10 had CKD stage 5 ie end stage CKD on haemodialysis, two stage 4 , and one each for stage 3 and stage 2 . Of those with CKD, 6 (43\%) had subsequent AKI on ICU admission (acute on chronic CKD). Thirty-seven patients $(25.8 \%)$ were dialysed. Of these, 14 had continuous renal replacement therapy, 21 intermittent haemodialysis, 1 Sustained Low Efficiency Dialysis and 1 peritoneal dialysis. Of the 37 dialysed patients, 33 were classified as $\mathrm{AKI}_{\text {uo }}$ and 4 as No $\mathrm{AKI}_{\mathrm{uo}}$.

Seven patients had cancer as pre-existing diseases. These include two with Acute Lymphoid Leukaemia (ALL), one each with Acute Myeloid Leukaemia (AML), Hodgkin lymphoma, advanced breast cancer, cervical cancer, and colon carcinoma. The patients with ALL, AML and Hodgkin lymphoma were classified as no $\mathrm{AKI}_{\mathrm{uo}}$. Whereas, those with more advanced cancers which includes breast cancer, cervical cancer and colon carcinoma had $\mathrm{AKI}_{\mathrm{uo}}$.

Of the 143 patients recruited, 34 received intravenous frusemide (Table 1). Of this, 9 had continuous infusion of frusemide of 5 to $10 \mathrm{mg} /$ hour for a maximum of 10 hours. Another 25 had boluses of frusemide at dose of 10 to $40 \mathrm{mg}$ stat. Twelve patients had nephrotoxic antibiotics given. These include vancomycin, gentamicin, polymyxin $E$, and acyclovir. There were no differences between $\mathrm{AKI}_{\text {uo }}$ and No $\mathrm{AKI}_{\mathrm{uo}}(\mathrm{p}=0.853)$. More patients with $\mathrm{AKI}_{\mathrm{uo}}$ had dialysis and more also died compared to those without $\mathrm{AKI}_{\mathrm{uo}}$. There were no differences in mechanical ventilation or its length, and also duration of ICU or hospital stay between patients with and without $\mathrm{AKI}_{\mathrm{uo}}$.

Diagnostic and predictive performance of $A K I_{\text {uo }}$ and $\cup O_{0.3}$

The diagnostic and predictive performance of 6-hour urine output was calculated using the area under receiver operating characteristics curve analysis. The mean (SD) of the minimum urine output for a moving block of 6 hour for the first 48 hours for our cohort was $0.40(0.50) \mathrm{ml} / \mathrm{kg} /$ hour (Table 2).
Utilising this numerical value, the AUC for diagnosing $\mathrm{AKI}_{\mathrm{Cr}}$, predicting death and the need for dialysis were $0.79(0.71,0.86), 0.70(0.59,0.81)$ and $0.83(0.74,0.91)$ respectively. The optimal cutoff point which was determined from the maximal sensitivity and specificity was $0.35 \mathrm{ml} / \mathrm{kg} / \mathrm{h}$.

In Table 2, we also calculated the AUC of the new proposed cut-off point $\left(\mathrm{UO}_{0.3}\right)$, to the current cutoff point in the current $A K I$ guideline $\left(\mathrm{AKI}_{\mathrm{uo}}\right)$ for each outcome of $\mathrm{AKI}_{\mathrm{cr}}$, death and the need for dialysis. We showed that both cut-off points $\left(\mathrm{AKI}_{\mathrm{uo}}\right.$ and $\mathrm{UO}_{0.3}$ ) had fair performance for $\mathrm{AKI}_{\mathrm{Cr}}$, death and the need for dialysis, with AUC and the $95 \%$ confidence interval more than 0.5 .

Table 2: Moving 6-hour block of urine output in diagnosing $\mathrm{AKI}_{\mathrm{cr}}$, and predicting mortality and dialysis.

\begin{tabular}{llll}
\hline $\begin{array}{l}\text { Urine output } \\
\text { variables }\end{array}$ & $\begin{array}{l}\text { AUC for } \\
\mathrm{AKI}_{\mathrm{Cr}}\end{array}$ & $\begin{array}{l}\text { AUC for } \\
\text { mortality }\end{array}$ & $\begin{array}{l}\text { AUC for } \\
\text { dialysis }\end{array}$ \\
\hline Minimum urine & 0.79 & 0.70 & 0.83 \\
output & $(0.71$, & $(0.59$, & $(0.74$, \\
& $0.86)$ & $0.81)$ & $0.91)$ \\
$\mathrm{AKI}_{\text {uо }}$ & 0.71 & 0.62 & 0.69 \\
& $(0.62$, & $(0.51$, & $(0.60$, \\
$\mathrm{UO}_{0.3}$ & $0.80)$ & $0.72)$ & $0.78)$ \\
& 0.72 & 0.66 & 0.78 \\
& $(0.63$, & $(0.55$, & $(0.69$, \\
& $0.80)$ & $0.77)$ & $0.87)$
\end{tabular}

Data expressed as Area Under Curve (AUC) with 95\% confidence interval. These were analysed using the receiver-operating characteristic curve $(\mathrm{ROC})$ curve of the sensitivity (true positive rate) against 1 -specificity (false positive rate) across a series of cut-off points. AKI uo was defined if urine output less than $0.5 \mathrm{ml} / \mathrm{kg} / \mathrm{h}$, and $\mathrm{UO}_{0.3}$ less than $0.3 \mathrm{ml} / \mathrm{kg} / \mathrm{h}$. AKI $\mathrm{Cr}$ was defined as creatinine increase of more or equal to $26.5 \mathrm{mmol} / \mathrm{l}$ or more than $50 \%$ increase from baseline.

Multivariate analysis for diagnosing $A K I_{C r}$, and predicting death and the need for dialysis

Multivariate analyses were performed to investigate the independent contributions of $\mathrm{AKI}_{\mathrm{uo}}$ and $\mathrm{UO}_{0.3}$ in diagnosing $\mathrm{AKI}$ and predicting death and the need for dialysis.

Severity of illnesses was calculated by the APACHE II and SOFA scores. However, since both scores are linearly related $(\mathrm{r}=0.57, \mathrm{p}<0.0001)$, and both are using almost similar variables, only SOFA score was included as covariate. Age, sepsis, chronic renal failure (CRF), diabetes mellitus (DM), and SOFA score were included as covariates, and backward stepwise logistic regression automatic variable selection procedure was used for diagnosing $\mathrm{AKI}_{\mathrm{Cr}}$, predicting death and the need for dialysis (Table 3 ). 
Table 3: Multivariate logistic regression analysis for diagnosing $\mathrm{AKI}_{\mathrm{cr}}$, and predicting death and the need for dialysis

\begin{tabular}{|c|c|c|c|}
\hline & $\begin{array}{l}\text { Diagnosing } \\
\mathrm{AKI}_{\mathrm{cr}}\end{array}$ & $\begin{array}{l}\text { Prediction } \\
\text { of } \\
\text { mortality }\end{array}$ & $\begin{array}{l}\text { Prediction } \\
\text { of the } \\
\text { need for } \\
\text { dialysis }\end{array}$ \\
\hline $\begin{array}{l}\mathrm{AKI}_{\text {uo }} \text { (no } \mathrm{AKI}_{\text {uo }} \text { as } \\
\text { reference) }\end{array}$ & $\begin{array}{l}4.40(2.00, \\
9.69)\end{array}$ & $\begin{array}{l}2.50 \\
(0.98 \\
6.40)\end{array}$ & $\begin{array}{l}5.40 \\
(1.72 \\
16.9)\end{array}$ \\
\hline \multicolumn{4}{|l|}{$\begin{array}{l}\text { Variables } \\
\text { included }\end{array}$} \\
\hline - Age (year) & $\begin{array}{l}1.03(1.00, \\
1.05)\end{array}$ & & \\
\hline \multicolumn{4}{|l|}{$\begin{array}{l}\text { - Sepsis (no } \\
\text { sepsis as } \\
\text { reference) }\end{array}$} \\
\hline $\begin{array}{l}\text { - Chronic renal } \\
\text { failure (CRF) } \\
\text { (no CRF as } \\
\text { reference) }\end{array}$ & & & $\begin{array}{l}8.52 \\
(1.99 \\
36.6)\end{array}$ \\
\hline $\begin{array}{l}\text { - } \text { Diabetes } \\
\text { mellitus (DM) } \\
\text { (no DM as } \\
\text { reference) }\end{array}$ & $\begin{array}{l}2.34(0.84, \\
6.51)\end{array}$ & & \\
\hline $\begin{array}{l}\text { - SOFA without } \\
\text { renal score } \\
\text { (unit) }\end{array}$ & $\begin{array}{l}1.13(0.99, \\
1.28)\end{array}$ & $\begin{array}{l}1.19 \\
(1.04 \\
1.37) \\
\end{array}$ & $\begin{array}{l}1.17 \\
(1.01 \\
1.35)\end{array}$ \\
\hline $\begin{array}{l}\mathrm{UO}_{0.3} \text { (no } \mathrm{UO}_{0.3} \text { as } \\
\text { reference) }\end{array}$ & $\begin{array}{l}10.2(3.64, \\
28.6)\end{array}$ & $\begin{array}{l}2.77 \\
(1.16 \\
6.56)\end{array}$ & $\begin{array}{l}9.82 \\
(3.87 \\
24.9)\end{array}$ \\
\hline \multicolumn{4}{|l|}{$\begin{array}{l}\text { Variables } \\
\text { included }\end{array}$} \\
\hline - Age (year) & $\begin{array}{l}1.03(1.01, \\
1.06)\end{array}$ & & \\
\hline $\begin{array}{l}\text { - Sepsis (no } \\
\text { sepsis as } \\
\text { reference) }\end{array}$ & & & \\
\hline $\begin{array}{l}\text { - Chronic renal } \\
\text { failure (CRF) } \\
\text { (no CRF as } \\
\text { reference) }\end{array}$ & & & $\begin{array}{l}5.65 \\
(1.23 \\
26.1)\end{array}$ \\
\hline $\begin{array}{l}\text { Diabetes } \\
\text { mellitus (DM) } \\
\text { (no DM as } \\
\text { reference) }\end{array}$ & & & \\
\hline $\begin{array}{l}\text { - SOFA without } \\
\text { renal score } \\
\text { (unit) }\end{array}$ & & $\begin{array}{l}1.15 \\
(1.00 \\
1.33)\end{array}$ & \\
\hline
\end{tabular}

Data presented as OR and $95 \%$ confidence interval. Age, sepsis, CRF, DM, and SOFA score were included as covariates, and backward stepwise logistic regression automatic variable selection procedure was used. $\mathrm{AKI}_{\text {uo }}$ and $\mathrm{UO}_{0.3}$ were analysed separately. $\mathrm{AKI}_{\text {uo }}$ was defined if urine output less than $0.5 \mathrm{ml} / \mathrm{kg} / \mathrm{h}$, and $\mathrm{UO}_{0.3}$ less than 0.3 $\mathrm{ml} / \mathrm{kg} / \mathrm{h}$. $\mathrm{AKI}_{\mathrm{cr}}$ was defined as creatinine increase of more or equal to $26.5 \mathrm{mmol} / \mathrm{l}$ or more than $50 \%$ increase from baseline.

Both $\mathrm{AKI}_{\text {ио }}$ and $\mathrm{UO}_{0.3}$ independently diagnosed $\mathrm{AKI}_{\mathrm{cr}}$ (OR of $4.40(2.00,9.69)$ and 10.2 (3.64, 28.6), respectively. Age, DM and SOFA score were included in the final model for $A K I_{\text {uo }}$, whilst only age remained for $\mathrm{UO}_{0.3}$. For prediction of death, only
$\mathrm{UO}_{0.3}$ was independently predictive (OR of 2.77 $(1.16,6.56)$, whereas $\mathrm{AKI}_{\text {uо }}$ was not (OR of 2.50 $(0.98,6.40)$. For both, SOFA score remained as covariates. Whereas, for prediction of the need for dialysis, both $\mathrm{AKI}_{\mathrm{uo}}$ and $\mathrm{UO}_{0.3}$ were independently predictive, where CRF remained as covariates.

\section{Survival Analysis}

There was lower survival in patients with $\mathrm{AKI}_{\mathrm{uo}}$ and $\mathrm{UO}_{0.3}$ compared to those without $(\mathrm{p}=0.01$, and 0.001 , respectively; Figure 2). However, after adjusting for covariates (age and SOFA score without renal score), only $\mathrm{UO}_{0.3}$ but not $\mathrm{AKI}_{\text {uo }}$ was an independent risk factor for death (HR 2.44 (1.15 to 5.18).

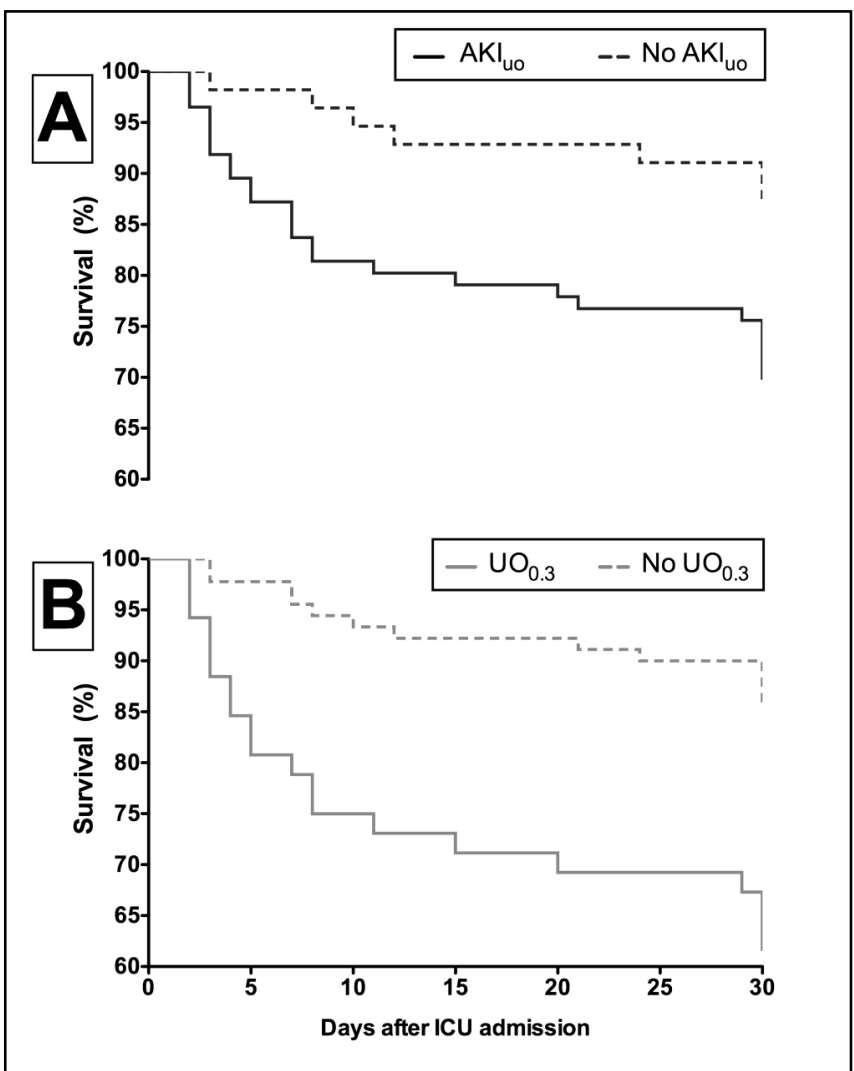

Figure 2: Survival analyses between patients with and without AKluo (A), and UOO.3 (B). Kaplan-Meier analyses, $\mathrm{p}=0.01(\mathrm{~A})$, and $0.001(\mathrm{~B})$.

Optimal cut-off point for each duration of urine output assessment

We analysed the AUC and cut-off point for each duration of urine output assessed over a moving block of 1 to 12 hour in predicting death (Table 4). The AUC of urine output assessed for 2 hours or longer were predictive of death, whereas that was assessed over 1 hour was not. In addition, the optimal cut-off point for each duration ranges from 0.21 to $0.40 \mathrm{ml} / \mathrm{kg} / \mathrm{hour}$. The cut-off point increased with increasing duration of assessment from 2 to 12 hours. The cut-off point for 6-hour urine output assessment was $0.35 \mathrm{ml} / \mathrm{kg} /$ hour. 
Table 4: Optimal cut-off point for prediction of death for different duration of urine output assessment

\begin{tabular}{|c|c|c|c|c|}
\hline $\begin{array}{l}\text { Duration of } \\
\text { assessment }\end{array}$ & $\begin{array}{l}\text { AUC } \\
(95 \% \\
\text { Cl) }\end{array}$ & $\begin{array}{l}\text { Optimal } \\
\text { cut-off } \\
\text { point } \\
(\mathrm{ml} / \mathrm{kg} / \mathrm{h})\end{array}$ & Sensitivity & Specificity \\
\hline 1 hour & $\begin{array}{l}0.60 \\
(0.49, \\
0.71)\end{array}$ & 0.40 & $\begin{array}{l}0.25(0.17, \\
0.34)\end{array}$ & $\begin{array}{l}0.79(0.65 \\
0.93)\end{array}$ \\
\hline 2 hours & $\begin{array}{l}0.65 \\
(0.55, \\
0.75)\end{array}$ & 0.21 & $\begin{array}{l}0.59(0.50, \\
0.68)\end{array}$ & $\begin{array}{l}0.76(0.61, \\
0.90)\end{array}$ \\
\hline 3 hours & $\begin{array}{l}0.68 \\
(0.59, \\
0.78)\end{array}$ & 0.24 & $\begin{array}{l}0.62(0.53, \\
0.71)\end{array}$ & $\begin{array}{l}0.76(0.61, \\
0.90)\end{array}$ \\
\hline 4 hours & $\begin{array}{l}0.69 \\
(0.59, \\
0.78)\end{array}$ & 0.29 & $\begin{array}{l}0.64(0.55, \\
0.73)\end{array}$ & $\begin{array}{l}0.76(0.61, \\
0.90)\end{array}$ \\
\hline 5 hours & $\begin{array}{l}0.69 \\
(0.59, \\
0.78)\end{array}$ & 0.29 & $\begin{array}{l}0.68(0.59, \\
0.77)\end{array}$ & $\begin{array}{l}0.73(0.58, \\
0.88)\end{array}$ \\
\hline 6 hours & $\begin{array}{l}0.70 \\
(0.61, \\
0.79)\end{array}$ & 0.35 & $\begin{array}{l}0.66(0.58, \\
0.75)\end{array}$ & $\begin{array}{l}0.79(0.65, \\
0.93)\end{array}$ \\
\hline 7 hours & $\begin{array}{l}0.69 \\
(0.60 \\
0.79)\end{array}$ & 0.33 & $\begin{array}{l}0.70(0.61, \\
0.79)\end{array}$ & $\begin{array}{l}0.67(0.51, \\
0.83)\end{array}$ \\
\hline 8 hours & $\begin{array}{l}0.69 \\
(0.60, \\
0.79)\end{array}$ & 0.34 & $\begin{array}{l}0.70(0.61, \\
0.79)\end{array}$ & $\begin{array}{l}0.67(0.51, \\
0.83)\end{array}$ \\
\hline 9 hours & $\begin{array}{l}0.68 \\
(0.58, \\
0.77)\end{array}$ & 0.34 & $\begin{array}{l}0.71(0.62, \\
0.79)\end{array}$ & $\begin{array}{l}0.64(0.47 \\
0.80)\end{array}$ \\
\hline 10 hours & $\begin{array}{l}0.68 \\
(0.58, \\
0.78)\end{array}$ & 0.35 & $\begin{array}{l}0.71(0.62, \\
0.79)\end{array}$ & $\begin{array}{l}0.64(0.47 \\
0.80)\end{array}$ \\
\hline 11 hours & $\begin{array}{l}0.69 \\
(0.59, \\
0.78)\end{array}$ & 0.40 & $\begin{array}{l}0.70(0.61, \\
0.79)\end{array}$ & $\begin{array}{l}0.67(0.51, \\
0.83)\end{array}$ \\
\hline 12 hours & $\begin{array}{l}0.69 \\
(0.59, \\
0.78)\end{array}$ & 0.40 & $\begin{array}{l}0.72(0.63, \\
0.80)\end{array}$ & $\begin{array}{l}0.67(0.51, \\
0.83)\end{array}$ \\
\hline
\end{tabular}

Area under curve (AUC), sensitivity and specificity were expressed with 95\% confidence interval. These were analysed using the receiver-operating characteristic curve (ROC) curve of the sensitivity (true positive rate) against 1 -specificity (false positive rate) across a series of cut-off points. The optimal cut-off points were determined as the measured quantity, which maximised sensitivity and specificity.

\section{DISCUSSION}

In this prospective study, we showed that AKI by the current urine output criteria of $\leq 0.5 \mathrm{ml} / \mathrm{kg} / \mathrm{h}$ occurred in $60 \%$ of our patients. Of this, almost half had urine output of $\leq 0.3 \mathrm{ml} / \mathrm{kg} / \mathrm{h}$. The lower threshold of urine output criteria was independently associated with death, whereas the current criteria was not. Duration of urine output as short as 2 hours can be used when utilising the stricter definition, whereas duration of 6 hours is needed using the standard criteria. We also showed that both criteria were independently associated with development of AKI by creatinine criteria and the need for dialysis.

In the intensive care setting, urine output is routinely measured, hence is a useful rapid indicator of kidney function. Inclusion of urine output criteria in the AKI definition increases the incidence of AKI, and these were associated with higher risk of death. ${ }^{7,11}$ We have previously showed that the addition of urine output criteria for AKI diagnosis increases its incidence from $38 \%$ to $65 \% .^{13}$ Patients with $\mathrm{AKI}_{\text {uo }}$ but no $A K \mathrm{I}_{\mathrm{cr}}$ were more than twice as likely to die compared to patients without AKI. In a large study involving about 1600 patients, ${ }^{18}$ AKI by urine output criteria alone increased the risk for death compared to patients without AKI, increasing with AKI severity.

Urine output criterion was initially included in the AKI definition by the group based on expert consensus amongst intensivists and nephrologists. ${ }^{2}$ This was later incorporated in the AKIN and KDIGO. ${ }^{3,4}$ However, this threshold has been less validated compared to the creatinine criteria. Recently, Ralib et al. $^{6}$ investigated the ideal threshold of urine output in predicting hard outcome of death or the need for dialysis in 725 intensive care admissions in a single centre. They showed that a threshold of $0.3 \mathrm{ml} / \mathrm{kg} / \mathrm{h}$ for moving block of 6 hours urine output ideally predicted death or the need for dialysis. Similar to this, we showed the cut-off point from our cohort to be 0.35 $\mathrm{ml} / \mathrm{kg} / \mathrm{h}$.

We investigated this new threshold for predicting death in our ICU patients using a multivariate analysis to adjust for other confounding factors. We showed that using a moving 6-hour block, urine output of $\leq 0.3 \mathrm{ml} / \mathrm{kg} / \mathrm{h}$ but not $0.5 \mathrm{ml} / \mathrm{kg} / \mathrm{h}$ independently predicted death after adjusting for age and severity of illness. In contrast, in a large retrospective study involving more than 20,000 patients, Zhang et al. ${ }^{19}$ showed that both urine output thresholds were independently predictive of death. This study investigated urine output for the first 24 hours of ICU admission, whereas our study extends the assessment over the first 48 hours of ICU admission. This is because we would like to adjust for any variables in the urine output that may have resulted from acute resuscitation that may have occurred during the first 24 hours of ICU admission.

Duration of urine output assessment is also important in assessing the clinical applicability and feasibility of urine output criteria. The longer the duration will limit its clinical applicability, whereas the shorter the duration will be non specific due to influences from other factors such as intravenous fluid, use of diuretics or presence of obstruction etc. Ralib et al. ${ }^{6}$ showed that urine output assessed over 3 to 9 hours best predicted death or the need for dialysis, with the ideal threshold being $[(0.03 \times$ duration of assessment) +0.11$] \mathrm{ml} / \mathrm{kg} / \mathrm{h}$. In this study, we showed that at least 2 hours are needed for optimal prediction of death This support the suggestion of oliguria over 2 consecutive hours for early recognition. ${ }^{20}$ This study also demonstrated that the optimal cut-off point increased with 
increasing duration of urine output assessment from 2 to 12 hours. for 6 -hour urine output assessment is $0.35 \mathrm{ml} / \mathrm{kg} / \mathrm{hour}$. This supports the previous finding by Ralib et al.

In this study, we also assessed the ability of urine output to diagnosed AKI by the creatinine criteria. Both $\mathrm{AKI}_{\text {uo }}$ and $\mathrm{UO}_{0.3}$ diagnosed $\mathrm{AKI}_{\mathrm{Cr}}$ after adjusting for age, diabetes mellitus, and SOFA score. In a multicentre study involving 239 patients, Prowle et al. ${ }^{8}$ studied the diagnostic capability of consecutive hours of oliguria in diagnosing the development of AKI by creatinine criteria on the next day. They showed that oliguria of at least 1 hour diagnosed $\mathrm{AKI}_{\mathrm{Cr}}$, with an AUC of 0.75 (0.64 to 0.50$)$.

Urine output is often used as one of indicator for fluid resuscitation in the intensive care unit. There are increasing evidences of detrimental effect of a positive fluid balance in the critically ill. ${ }^{21-23}$ Hence, a lower urine output threshold than currently practice for fluid resuscitation may reduce the extent of any positive fluid balance and the associated adverse outcomes. ${ }^{6}$ Nevertheless, a threshold of $0.5 \mathrm{ml} / \mathrm{kg} / \mathrm{h}$ is still useful, as a warning for impending negative outcome. However, a threshold of $0.3 \mathrm{ml} / \mathrm{kg} / \mathrm{h}$ may be a better target to trigger fluid loading.

\section{Study limitations}

There were several limitations of this study. First, it was performed in only one centre and involves a small number of patients. A further larger multicentre trial would provide a more robust data. Second, only 48 hours data of urine output were analysed to detect AKI by urine output data. We may have missed those who developed AKI later in their ICU admission. Future study involving longer duration of assessment may detect these. Third, body weight was not measured, but estimated. However, univariate analysis showed no differences in body weight between patients with and without AKI. Fourthly, we used the trend of central venous pressure (CVP) monitoring mainly to measure the volume status of these patients. We understand the limitation of using CVP as volume status indicator. In addition, since we utilise trending of CVP rather than the absolute value, it was not reported in this paper. Fifthly, we did not collect data on number of patient receiving contrast agent. We understand that this is an important precursor for AKI, however the overall number of critically ill patients who received and consequently developed Contrastinduced nephropathy (CIN) is low compared to other renal insults. CIN was reported to occur in only $2 \%$ of patients following radiocontrast agent administration. ${ }^{24}$ Finally, we used the first creatinine on ICU admission as baseline for $\mathrm{AKI}_{\mathrm{Cr}}$. This will detect those who developed AKI after ICU admission, and those with acute on chronic AKI, however with the limitation of those who developed AKI prior to ICU admission.

\section{CONCLUSION}

Sixty percent of our patients had 6-hour urine output of $\leq 0.5 \mathrm{ml} / \mathrm{kg} / \mathrm{h}$; of this, half had urine output of $\leq 0.3 \mathrm{ml} / \mathrm{kg} / \mathrm{h}$. A threshold of 6 hourly urine output of $0.3 \mathrm{ml} / \mathrm{kg} / \mathrm{h}$ but not $0.5 \mathrm{ml} / \mathrm{kg} / \mathrm{h}$ was independently predictive of death. Duration of urine output assessed for at least 2 hours is needed for optimal prediction. This support previous finding of a lower threshold of urine output criteria for optimal prediction. Both criteria are independently associated with $\mathrm{AKI}_{\mathrm{cr}}$ and dialysis commencement.

\section{CONFLICT OF INTEREST \\ None}

\section{ACKNOWLEDGEMENTS}

This study was partly funded by the Ministry of Higher Education Fundamental Research Grant Scheme (FRGS/1/2015/SKK02/UIAM/02/3). The result of the study has been presented in a poster presentation at the Annual Scientific Congress of the Malaysian Society of Anaesthesiologists and College of Anaesthesiologist and the $13^{\text {th }}$ Asian Society of Paediatric Anaesthesiologists, $11^{\text {th }}$ to $14^{\text {th }}$ June 2015. We would like to thank Amimah Abdul Hamid, Siti Nabilah Zainuddin, Nurhafizah Zarudin and all nurses in the intensive care unit for their assistance in data collection for the study. We also like to thank Norhalini Hamzah, Majdiah Syahirah Nasir, Wafa Mohamed El Taib, $4^{\text {th }}$ year medical students for collecting part of data for the study.

\section{REFERENCES}

1. Eknoyan G. Emergence of the concept of acute kidney injury. Adv Chronic Kidney Dis. 2008; 15:308-13.

2. Bellomo R, Ronco C, Kellum JA, Mehta RL, Palevsky P. Acute renal failure - definition, outcome measures, animal models, fluid therapy and information technology needs: the Second International Consensus Conference of the Acute Dialysis Quality Initiative (ADQI) Group. Crit Care. 2004; 8:R204-12.

3. Mehta R, Kellum J, Shah S, Molitoris BA, Ronco C, Warnock D et al. Acute Kidney Injury Network: report of an initiative to improve outcomes in acute kidney injury. Crit Care. 2007; 11:R31.

4. KDIGO. Clinical Practice Guideline for Acute Kidney Injury Section 2: AKI Definition. Kidney Int Suppl. 2012; 2:19-36

5. Bellomo R, Kellum JA, Ronco C. Defining and classifying acute renal failure: from advocacy to consensus and validation of the RIFLE criteria. Intens Care Med. 2007; 33:409-13.

6. Ralib AM, Pickering JW, Shaw GM, Endre ZH. The urine output definition of acute kidney injury is too liberal. Crit Care. 2013; 17:R112.

7. Macedo E, Malhotra R, Bouchard J, Wynn SK, Mehta RL. Oliguria is an early predictor of higher 
mortality in critically ill patients. Kidney Int. 2011; 80:760-7.

8. Prowle JR, Liu Y-L, Licari E, Bagshaw SM, Egi M, Haase $M$ et al. Oliguria as predictive biomarker of acute kidney injury in critically ill patients. Crit Care. 2011; 15:R172.

9. Wlodzimirow KA, Abu-Hanna A, Slabbekoorn M, Chamuleau RA, Schultz MJ, Bouman CS. A comparison of RIFLE with and without urine output criteria for acute kidney injury in critically ills. Crit Care. 2012; 16:R200.

10. Vanmassenhove J, Glorieux G, Hoste E, Dhondt A, Vanholder R, Van Biesen W. Urinary output and fractional excretion of sodium and urea as indicators of transient versus intrinsic acute kidney injury during early sepsis. Crit Care. 2013; 17:R234.

11. Macedo E, Malhotra R, Claure-Del Granado R, Fedullo P, Mehta RL. Defining urine output criterion for acute kidney injury in critically ill patients. Nephrol Dial Tranplant. 2011; 26:50915.

12. Cruz DN, Bolgan I, Perazella MA, Bonello M, de Cal $M$ et al. North East Italian Prospective Hospital Renal Outcome Survey on Acute Kidney Injury: targeting the problem with the RIFLE Criteria. Clinical J Am Soc Nephrol. 2007; 2:41825.

13. Md Ralib A, Mat Nor MB. Acute kidney injury in a Malaysian intensive care unit: Assessment of incidence, risk factors, and outcome. J Crit Care. 2015; 30:636-42.

14. Tripepi G, Jager KJ, Dekker FW, Zoccali C. Diagnostic methods 2: receiver operating characteristic (ROC) curves. Kidney Int. 2009; 76:252-6.

15. Bewick V, Cheek L, Ball J. Statistics review 13: Receiver operating characteristic curves. Crit Care. 2004; 8:508-12.

16. Cook NR. Use and misuse of the receiver operating characteristic curve in risk prediction. Circulation. 2007; 115:928-35.

17. Fluss R, Faraggi D, Reiser B. Estimation of the Youden Index and its associated cutoff point. Biom J. 2005; 47:458-72.

18. Han SS, Kang KJ, Kwon SJ, Wang SJ, Shin SH, Oh SW et al. Additional role of urine output criterion in defining acute kidney injury. Nephrol Dial Transplant. 2012; 27:161-5.

19. Zhang Z, Xu X, Ni H, Deng H. Urine output on ICU entry is associated with hospital mortality in unselected critically ill patients. J Nephrol. 2014; 27:65-71.

20. Rimmelé T, Kellum JA. Oliguria and Fluid Overload. Contrib Nephrol. 2010; 164:39-45.

21. Payen D, de Pont AC, Sakr $Y$, Spies $C$, Reinhart $\mathrm{K}$, Vincent JL. A positive fluid balance is associated with a worse outcome in patients with acute renal failure. Crit Care. 2008; 12:R74.

22. Bellomo R, Cass A, Cole L, Finfer S, Gallagher M, Lo $S$ et al. Intensity of continuous renal- replacement therapy in critically ill patients. New England J Med. 2009; 361:1627-38.

23. Vaara ST, Korhonen AM, Kaukonen KM, Nisula S, Inkinen $\mathrm{O}$, Hoppu $\mathrm{S}$ et al. Fluid overload is associated with an increased risk for 90-day mortality in critically ill patients with renal replacement therapy: data from the prospective FINNAKI study. Crit Care. 2012; 16:R197.

24. Cely CM, Schein RM, Quartin AA. Risk of contrast induced nephropathy in the critically ill: a prospective, case matched study. Crit Care. 2012; 16:R67. 